\title{
Potpourri: New strategies, funding, partnerships
}

W.R. GOMES

Vice President

Agriculture and Natural Resources

\footnotetext{
T
} The early 1990s brought the state's worst economic downturn in more than 50 years, and a series of budget cuts that sliced $20 \%$ from the Division's state funds. Today, California approaches the year 2000 fueled by a statewide business expansion and a budget surplus of $\$ 4.4$ billion. With the state's fortunes on the upswing, the Division is seeking a partial recovery of lost resources.

When the budget cuts began, we worked as an organization to build upon our strengths, knowing that we had entered an era of limited resources. The keystone of this effort was the creation and adoption of our divisionwide strategic plan. It included not only our vision for the future, but a budget system for allocating resources to high priority issues and problems facing agricultural and other clientele. While this plan will help us squeeze everything we can from limited resources, it can also provide guidance in allocating new funds.

With that in mind, we have worked hard to identify new funding sources, both public and private, obtaining needed facilities and expanding our partnerships with external stakeholders and supporters. Here is a sampling of recent, pertinent developments.

State budget augmentation: On June 15 the six-member Joint Legislative Conference Committee on the Budget reached agreement on several budget augmentations that will increase funding to the Division if passed by the Assembly and Senate, and if signed by Governor Pete Wilson.

The augmentation includes $\$ 5.5$ million to help restore UCCE programs and support agricultural research, $\$ 4$ million to fund a $0.4 \%$ pay increase for all non-Academic Senate employees of UC, including UCCE specialists and advisors, $\$ 2.5$ million to expand academic programs of the UCD School of Veterinary Medicine into Southern California, and $\$ 265,000$ for viticulture and enology competitive grants, contingent on an industry match.

New research money in Farm Bill: With our land grant colleagues, and with significant support from the California delegation, we were successful in convincing Congress to authorize an additional $\$ 120$ million in new research dollars, for each of the next 5 years. However, while the U.S. Senate has voted to appropriate the needed funds for FY1999, U.S. House of Representatives members did not. Differences between the House and Senate in providing these funds, which would more than double the USDA competitive research program, will not be resolved until September.

New quarantine and containment facilities: On July 2, UC Riverside broke ground for a new, state-of-the-art insectary and quarantine facility, which will be constructed over the next 24 months. Research carried out in the facility will focus on biological control and other alternative pest management strategies for the state's agricultural, urban and natural environments. The facility has been financed with both state and federal funds.

The UCR facility is one part of a DANR project which includes a pest quarantine and containment facility at UC Davis. The Davis facility will focus on biotechnology and the use of genetically engineered organisms to control plant and microbial pests. The University plans to have both facilities operational by the year 2001, but funding for the UC Davis facility is incomplete. We are hopeful that Congress will provide this funding in next year's budget.

Nutrition Center: The U.S. House of Representatives has approved $\$ 12.3$ million in FY1999 for construction of the USDA-ARS Western Human Nutrition Research Center on the UC Davis campus. This funding amount will be subject to negotiation in the conference committee; to date, the Senate has appropriated no money for the center.

Endowment for Natural Reserve System: The David and Lucile Packard Foundation has awarded a $\$ 4$ million endowment to the UC Natural Reserve System. Earnings from the new Kenneth S. Norris Endowment Fund for the California Environment will support new and renovated laboratories and lodgings, equipment and environmental monitoring at selected NRS sites through the state.

Transition team and reorganization: In June last year, acting on recommendations from the organizational strategy teams who have carried forward the strategic plan, we appointed a transition team to help develop and implement a more mission-based structure for DANR. After meeting monthly for a little more than a year, the team is now poised to present a plan for organizational restructuring of the Division.

President's Advisory Commission: Twenty-eight leaders in government, business, environmental protection, youth development and consumer protection, have accepted invitations to serve on UC President Richard Atkinson's Advisory Commission on Agriculture and Natural Resources. The Advisory Commission will allow us to expand interaction with stakeholder groups by providing them with direct access to the president of the University.

In short, we are developing meaningful ways to fulfill our mission and creative methods to finance those efforts. We are expanding the number of people involved in fulfilling our mutual goals, and we are reaching much further for funding opportunities to achieve these goals.

By developing new ways of doing things and identifying new partners we can move forward, utilizing both existing and new resources to best meet the challenges of the 21st century. 